\title{
Research on Hotel E-commerce Application Base on Convention and Exhibition Economy
}

\author{
Mengyi Lyu \\ School of Management, Shanghai University,200444 Baoshan Shanghai, China
}

\begin{abstract}
Convention and Exhibition Economy provides the new impetus for the development of hotel e-commerce. On the basis of theory related to Convention and Exhibition Economy, this paper expounds the connection between Convention and Exhibition Economy and the hotel e-commerce, then using the factor analysis method to study the hotel convention-class e-commerce usability evaluation indexes, finally the five common factors are extracted. The analysis shows that the hotel convention-class usability is influenced by the service efficiency, security assurance, operability, understandability, aesthetic effect, according to these indicators as well as the current situation of the development of the hotel exhibition business, some related suggestions are put forward in order to provide certain reference for the development of the hotel e-commerce.
\end{abstract}

\section{Introduction}

The advent of the Internet "plus" era makes e-commerce the focus of the development of numerous industries. According to the statistics of iResearch, the trade of online travel reservation market in China exceeded 500 billion yuan in 2017 , nearly one fifth of which was from the hotel online reservation business. It can be seen that e-commerce has injected new vitality into the hotel industry. With the major context of the new normal of Convention and Exhibition Economy, the hotels have the increasingly close links with the exhibition, meanwhile, the exhibition business has become the major part of the hotel management. As a traditional service industry, the hotel industry should seize the opportunity to achieve industrial linkage by making use of e-commerce technology and Convention and Exhibition Economy, while it should develop online products, to realize transformation and upgrading.

\section{The relationship between the new normal of convention and exhibition economy and the development of hotel e-commerce}

\subsection{Connotation of the new normal of convention and exhibition economy}

Convention and Exhibition Economy is a comprehensive economic form that is produced at a certain stage of the development of the exhibition industry, meanwhile, it is the existing form of economy that brings economic, cultural, political and other benefits by way of carrying out many types of convention and exhibition activities. It has the following three characteristics:

(1) Comprehensiveness

The exhibition industry constitutes Convention and Exhibition Economy together with numerous relevant industries. The exhibition industry and relevant industries support each other, making mutual development. Convention and Exhibition Economy covers a variety of trades, including tourism, the industry of transportation and communications industry, which is a comprehensive industry, as shown in figure 1 .

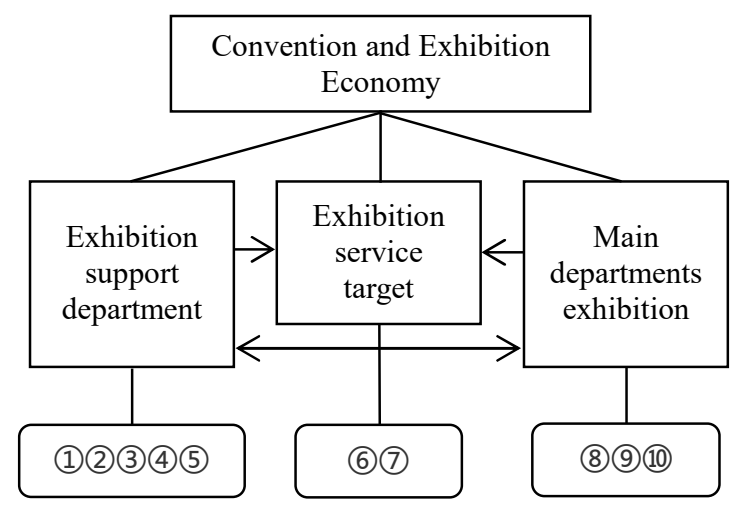
(1) Tourist industry (2) Catering industry
(3) Transportation industry (4) Communications industry
(5) Others (6) Exhibitor (7) Audience
(8) Exhibition organizer (9) Exhibition venue
(10) Exhibition contractor

Figure 1. Composition of Convention and Exhibition Economy.

a Corresponding author: 526032549@qq.com 


\section{(2) Industrial linkage}

Convention and Exhibition Economy has an extremely high degree of industrial linkage. Experts believe that the coefficient of exhibition industry promoting the development of related industries internationally is $1: 9$, that is to say the revenue of the exhibition venue per unit can bring the corresponding nine units of relevant industrial income, which makes Convention and Exhibition Economy the new economic growth point in numerous countries and regions. For example, the conference of "Fortune Forum" held in Guangzhou lasted only three days in 2017, but the cost in the various hotels in Guangzhou was amount to millions of dollars.

\section{(3) High profitability}

Convention and Exhibition Economy has an extremely high profit rate, which is usually over $20 \%$ to 25\%. Convention and Exhibition Economy has brought unprecedented prosperity in economy to many cities, such as Paris in France, New York in America and Hong Kong in China. The economic benefits of hosting more than 200 trade show a year in America exceed 3.8 billion dollars. The annual turnover of the French exhibition is up to 8.5 billion francs, while the trade volume of the exhibitors is up to 150 billion francs, in addition, the indirect consumption of the exhibitors as well as visitors is also about 25 billion francs. Hong Kong also makes considerable profits by hosting various large-scale conferences and exhibitions every year.

After decades of exploration and development, China's exhibition industry has already showed some new features of trades and change trend, while its industry scale, the functions of the government, ways of competition, region patterns are changing. Under the circumstances, the major background of numerous factors related to Convention and Exhibition Economy are seeking change and development is known as the "new normal of Convention and Exhibition Economy". At present, the number of exhibitions in China is increasing year by year, the geographical scope involved is constantly expanding, while the attention in the international exhibition market is increasing. According to the "Report on Chinese Exhibition Economy Development in 2017", China held 4022 exhibitions in total in 2017, which was involved in 100 exhibition organization units. The development of the domestic exhibition market was rapid, and it was about $3.82 \%$ higher than that in 2016, the exhibition markets about going abroad were also rising steadily. The structure of the exhibition industry chain is also being improved gradually, in addition, the number of the exhibition venues across the country is increasing year by year in terms of infrastructure. In terms of soft power, the demand for professional talents has increased sharply, and the exhibition education has risen in the whole country, so many preferential policies are released in various regions to retain the exhibition companies as well as the professional talents.

\subsection{Development opportunities of hotel e- commerce based on the new normal of convention and exhibition economy}

\subsubsection{Good economic benefits}

Convention and Exhibition Economy has high profit and high linkage, as a typical representative influenced by the exhibition industry's radiation effect, the hotel can not only provide the exhibition field for exhibition industry, but also catering, accommodation, entertainment and other services. Hotel provides the exhibition relevant services through electronic commerce, so the computer technology and information systems can be used to coordinate, control operation in the interior of the hotel, to realize the scientific management; in the outside part of the hotel, the hotel can optimize business model, rich the variety of product, realize the efficient cooperation with the enterprises related to the convention and exhibition, to create good economic benefits.

\subsubsection{Wide application scope, strong operability}

The exhibition services provided by the hotel are involved in consulting, reservation, hosting, feedback and other aspects, all of which can be realized through the hotel's official website, WeChat official account and other new media. Compared with the traditional management means, e-commerce possesses the features of globalization, timeliness, interactivity, security, etc., by way of the electronic commerce, the hotel could keep the real-time communication with the companies related to the exhibition, deploy all the available resources, to realize effective and fast communication and transaction.

\subsubsection{Sustainable optimization of policy development environment}

The government attaches great importance to Convention and Exhibition Economy, accordingly multiple policies have been introduced successively to optimize the industrial environment. "Some Suggestions on Further Promoting the Reform and Development of Exhibition Industry" promulgated by the State Council clearly points out that it needs to carry out the reform and innovation, improve market conditions, strengthen policy guidance. In 'the 13th Five-year Plan for the Development of Service Trade", the strategic layout and safeguard measures, etc. of service trade are listed in detail. Local governments at all levels have also issued the corresponding exhibition industry supporting policies. As an innovative development model of Convention and Exhibition Economy, hotel e-commerce has a good policy environment.

\section{Usability evaluation of e-commerce related to hotel exhibition}

\subsection{Evaluation method}


Usability refers to the effectiveness, efficiency and users' satisfaction of a product when it is used by users in a certain environment for formulating its purpose. To develop e-commerce related to hotel exhibition, its usability must be improved. Electronic commerce of the hotel is mainly implemented through the official website of the hotel, as a result, with the hotel's official website as the main part of the survey, the exhibition guests as the investigation objectives, it determines the usability evaluation index of the electronic commerce related to the hotel exhibition. First, this paper collected data by way of questionnaire survey, took the Shanghai International Exhibition Center as the investigation site, then a questionnaire survey was conducted by a random sample of the exhibitors as well as the visitors of the exhibition during June to August in 2017, and a total of 432 questionnaires were collected, at last, 386 valid questionnaires were got by getting rid of the questionnaires with omission or repeated answers, the valid rate concerning it was $89.3 \%$. Factor analysis was carried out on the collected data to determine the usability evaluation indexes of the e-commerce related to the hotel exhibition, so as to provide direction for improving the usability of the hotel e-commerce.

\subsection{Selection of evaluation indicators and factor analysis}

The usability of e-commerce is different from that of general products. It could enable consumers to know and obtain products or services at will without the limitation of time and place. Therefore, it should possess the features of being personalized, interactive and diversified and so on. By reference to the mobile e-commerce usability index system proposed by Gao Guowei, Zhang $\mathrm{Na}$, Zhang Pingchun ${ }^{3}$, with the combination of the characteristics of convention and exhibition itself, the paper constructs the usability evaluation index system from the level of service efficiency, security assurance, operability, understandability and aesthetic effect.

The factor analysis of the usability evaluation index was conducted by using SPSS19.0. First, the validity test was carried out, and it gained that the value of KMO was 0.846 , indicating that each variable had the relatively high partial correlation. Bartlett's sphericity test of Sig was equal to zero, which showed that the value of each index had a certain relationship, which was suitable for factor analysis.

Table 1. Results of validity test

\begin{tabular}{|c|c|c|}
\hline \multicolumn{2}{|c|}{$\begin{array}{c}\text { The Kaiser meyer-olkin measure with } \\
\text { sampling adequacy }\end{array}$} & .846 \\
\hline \multirow{4}{*}{ Bartlett's sphericity test } & $\begin{array}{c}\text { The approximate } \\
\text { chi-square }\end{array}$ & 808.704 \\
\cline { 2 - 3 } & $\mathrm{df}$ & 24 \\
\cline { 2 - 3 } & Sig. & .000 \\
\hline
\end{tabular}

The principal component method was used to extract the common factors; accordingly, five common factors were obtained, indicating that the extracted common factors retained most of the information of the original data. Then orthogonal rotation of the factor loading matrix was carried out by using the method of maximum variance, the related results were shown in table 2 . The load concerning the details and accuracy of the exhibition information (Q1 \& Q2), the convenience of searching information (Q3), the reaction speed of web page operation (Q4), the timeliness of customer service feedback (Q5) was higher on the first main factor, meanwhile, the above indicators mainly reflected the pertinence of exhibition information, which can be interpreted as service efficiency (F1). The convenience of placing orders (Q6) and the clarity and accuracy of service navigation (Q7) had a higher load on the second main factor. These indicators were mainly relevant to user's ease of operation, which can be interpreted as operability (F2). The language expression (Q8) and the classification (Q9) and typesetting (Q10) of the exhibition information had a higher load on the third main factor, which can be interpreted as understandability(F3). The load concerning the reliability of the website (Q11), the security of payment system (Q12), the reliability of the evaluation system (Q13) and confidentiality of user's information (Q14) was higher on the fourth main factor, and these indexes were related to the user's information and property safety, which can be interpreted as security assurance(F4). The aesthetic of the web page layout (Q15), the ease of color collocation (Q16) as well as the coordinating degree of illustrations and animation (Q17) mainly reflected the aesthetic of the web page, the above indicators had the higher load on the fifth main factor, and it can be interpreted as aesthetic effect (F5).

Table 2. Factor loading matrix after rotation.

\begin{tabular}{|c|c|c|c|c|c|c|}
\hline \multirow{2}{*}{\multicolumn{2}{|c|}{ Indicators }} & \multicolumn{5}{|c|}{ Main Factor } \\
\hline & & F1 & F2 & F3 & F4 & F5 \\
\hline \multirow{5}{*}{ F1 } & Q1 & .535 & .312 & .176 & .162 & .238 \\
\hline & Q2 & .670 & .002 & .283 & .075 & .060 \\
\hline & Q3 & .422 & .286 & .310 & .143 & .089 \\
\hline & Q4 & .716 & .003 & .220 & .245 & -.003 \\
\hline & Q5 & .321 & .288 & .601 & .159 & .198 \\
\hline \multirow{2}{*}{$\mathrm{F} 2$} & Q6 & .380 & .706 & .059 & .358 & .541 \\
\hline & Q7 & .289 & .646 & .183 & -.058 & .528 \\
\hline \multirow{3}{*}{ F3 } & Q8 & .123 & .281 & .506 & .162 & .199 \\
\hline & Q9 & .128 & .288 & .606 & .140 & .098 \\
\hline & Q10 & .021 & .253 & .342 & .144 & .125 \\
\hline \multirow{4}{*}{ F4 } & Q11 & .164 & -.013 & .210 & .709 & .275 \\
\hline & Q12 & .179 & .321 & .372 & .616 & -.023 \\
\hline & Q13 & .261 & .438 & .069 & .464 & -.007 \\
\hline & Q14 & .147 & .181 & -.004 & .735 & .046 \\
\hline \multirow{3}{*}{ F5 } & Q15 & .038 & .411 & .148 & .606 & .747 \\
\hline & Q16 & .101 & .301 & .309 & .248 & .399 \\
\hline & Q17 & .549 & .531 & .122 & .077 & .609 \\
\hline
\end{tabular}

\section{Equations and mathematics}

\subsection{Perfect the exhibition information on online platform, improve service efficiency}

At present, the online platform of the hotel mainly includes the following two major kinds: the official website as well as WeChat official account in the interior 
of the hotel and the intermediary platforms in the outside part of the hotel. The majority of the exhibition customers will choose understanding of the hotel information through the hotel's official website and WeChat official account, as a result, the hotel should set up the pages related to the exhibition in the official website as well as WeChat official account, in addition to the basic information, it also should be able to complete the reservation of the exhibition activities directly. For tourism, group purchase and other intermediary websites, customers generally make reservation for their rooms or dining in this way, as a result, the introduction about convention and exhibition services can be added to the column of the detailed information of the hotel, to expand the target customers. Besides, the hotel can cooperate with the professional exhibition services websites, such as the international convention and exhibition centers of various provinces and cities, while the hotel can add advertising in these websites, mark the exhibition service information that the hotel can provide, to improve the pertinence of convention and exhibition services.

At the same time, the hotel should pay attention to the operation and maintenance of online platform, maintain the relatively high response speed of web page, regulate the service time of the online customer service, improve the effectiveness of communication, so as to improve the overall service efficiency.

\subsection{Create a Good Operating Environment, Enhance Technical Power and Security}

The application of hotel e-commerce in China is still in the initial stage. There is still a gap between the operating environment of hotel e-commerce and the consumption demands of exhibition customers. The problems of the classification of convention and exhibition business are not clear, the relevant navigation fails to be determined, the personal information leakage occurs and so on, cause most of the exhibition customers choosing the pattern of querying online and trading offline, which greatly limits the development of the functions of electronic commerce that are related to the hotel exhibition.

Therefore, the relevant technologies should be continuously improved. First of all, the hotel should strengthen the website construction of the interior, comprehensively optimize the typesetting, classification and navigation of the exhibition information of the web page, pay attention to language expression, to improve the understandability of the exhibition information. Second, the hotel should enrich the functions of electronic commerce related to the exhibition, provide the services of information search, consulting, placing an order, payment, feedback, etc., in addition, the corresponding secondary functions also can be added, such as the traffic facilities, catering entertainment, travel information, making use of the electronic commerce to realize the all-round integrated service. Third, the hotel should adapt to the development trend of mobile ecommerce, strengthen the application of the exhibitionclass electronic commerce on the mobile end, such as the development of professional hotel exhibition services App, to enhance the pertinence of the targeted customers.

At the same time, in the process of the hotel ecommerce operations, the hotel should constantly focus on the safety of the online platform, pay attention to customers' personal information and property security, perfect the credit evaluation system, which provides a good guarantee for the subsequent operation of the hotel.

\subsection{Meet Customers' Aesthetic Needs, Pay Attention to the Aesthetic of Online Platforms}

At present, the online platforms' types are various, while the number of them is huge. In order to attract the public, the online platform must cater to the aesthetic needs of consumers, establish a good brand image. The hotel industry and exhibition industry are both typical servicetype trades, and the appearance of product is the important reflection of its connotation. Therefore, the hotel should pay attention to the aesthetic degree of the online platform, the layout of the web page should be reasonable, the mild and generous colors should be chosen for the collocation, the illustrations and animation should be applied moderately, accordingly the customers' comfort in using the online platform is improved.

\subsection{Flexible Adjustment of Business Strategy, Maximize E-commerce Functions}

Based on the background of "Internet plus", customers have many kinds of demands, while the updating speed of product is fast. Hotels should adhere to e-commerce as an important development module and continue to innovate products. For example, the development momentum of new media, such as WeChat, weibo, short video platform is rapid and strong, the hotel can conform to the trend, release exhibition information on the new media platforms, meanwhile, it also can create exclusive topic, conduct the promotion by uniting the celebrity of platform to show the power of the hotel. At the same time, the hotel can analyze the real evaluation and consumption experience of customers in real time, a customer communication platform can be set up to convey the core value of the hotel to customers imperceptibly, to build the brand image. On the mode of operation, the hotel can innovatively adopt franchise, service outsourcing and other means, in addition, the hotel can also cooperate with the professional e-commerce company, make use of its professional power to improve the strength of the hotel, to seek more competitive advantages. In a word, the hotel should review the situation, seeking the best management strategy to develop e-commerce.

\section{Conclusion}

To sum up, the new normal of Convention and Exhibition Economy provides a new development direction for hotel e-commerce. Hotels should take advantage of the linkage effect of Convention and Exhibition Economy to seek greater profit space. In order to give full play to the functions of e-commerce, hotels should be based on the 
service efficiency, operation environment, customers' aesthetic needs and other aspects to continuously improve the online services related to exhibition. At the same time, the seniors of the hotel should review the situation, flexibly formulate the operation strategy according to the market change, and take e-commerce as the means to realize the innovative development of the hotel.

\section{References}

1. G. Guowei, Z. Na, Z. Chunping, Elec.C, 5, 31 (2015).

2. H. Clark, H. Conjoint, J.Trvl. Res, 2, 62-69 (1996).

3. K. Weber, C. Restaurant. Tech.M.M, 8, 32-38 (2000).

4. L. Guolin, Sw.T, 14, 37-42 (2005).

5. L. Yun, CHN. C\&E, 23.32-39 (2014). 